\title{
Despatologização da homossexualidade e transexualidade: revisão integrativa
}

\section{Depathologization of homosexuality and transexuality: an integrative review}

\section{Despatologización de la homosexualidad y transexualidad: revisión integrativa}

Recebido: $18 / 07 / 2018$

Aprovado: 10/03/2019

Publicado: 01/07/2019

\author{
Jhonatan Costa Back ${ }^{1}$ \\ Laura Mendes da Silva ${ }^{2}$ \\ Layenne Prado ${ }^{3}$ \\ Luiz Arthur Rangel Cyrino ${ }^{4}$
}

Este estudo tem como objetivo identificar discursos referentes à despatologização da homossexualidade e da transexualidade presentes na produção acadêmica e nos posicionamentos técnico-científicos. Trata-se de uma revisão integrativa nas bases de dados online: SciELO, Scopus, PePSIC e Google Acadêmico, perfazendo 30 artigos levantados entre agosto de 2017 até fevereiro de 2018, considerando o período de 2000 a 2017, independente do idioma, com os descritores: patologia, transexualidade e homossexualidade. Apesar da homossexualidade não ser considerada um transtorno mental pela Associação Americana de Psiquiatria e pela Organização Mundial da Saúde, fora da comunidade científica ela é tratada como tal, gerando a homofobia. Já a transexualidade ainda é caracterizada como um transtorno mental pelas mesmas instituições. Assim, enfatiza-se como a cultura pode transpassar os sujeitos e incutir concepções de normalidade, as quais infringem as fronteiras da livre-expressão e da subjetividade.

Descritores: Patologia; Transexualismo; Homossexualidade.

This study aims to identify discourses regarding the depathologization of homosexuality and transexuality in academic production, as well as their technical-scientific positions. This is an integrative review in the online databases: SciELO, Scopus, PePSIC, and Google Scholar, which found 30 articles from August 2017 to February 2018, about the period from 2000 to 2017, regardless of language, with the descriptors: pathology, transexuality and homosexuality. Homosexuality is not considered a mental disorder by the American Psychiatric Association or the World Health Organization, but, outside the scientific community, it is treated as such, leading to homophobia. Transsexuality, on the other hand, is still characterized as a mental disorder by the same institutions. This situation highglights some of the ways in which culture can cross subjects and instill conceptions of normality, which infringe the boundaries of free expression and subjectivity. Descriptors: Pathology; Transsexualism; Homosexuality.

Este estudio tiene como objetivo identificar discursos referentes a la despatologización de la homosexualidad y de la transexualidad presentes en la producción académica y las posiciones técnico-científicas. Se trata de una revisión integrativa en las bases de datos online: SciELO, Scopus, PePSIC y Google Académico, totalizando 30 artículos levantados entre agosto de 2017 hasta febrero de 2018, considerando el período de 2000 a 2017, independiente del idioma, con los descriptores: patologia, transexualidade y homosexualidade. A pesar de la homosexualidad no ser considerada un trastorno mental por la Asociación Americana de Psiquiatría y por la Organización Mundial de la Salud, fuera de la comunidad científica es tratada como tal, generando la homofobia. Ya la transexualidad aún es caracterizada como un trastorno mental por las mismas instituciones. Así, se enfatizan las formas como la cultura puede traspasar los sujetos e inculcar concepciones de normalidad, las cuales, infringen las fronteras de la libre expresión y de la subjetividad.

Descriptores: Patología; Transexualismo; Homosexualidad.

1. Discente do curso de Psicologia da Universidade da Região de Joinville (UNIVILLE), Joinville, SC, Brasil. ORCID: 0000-0002-6754-2475 E-mail: costanatan7@gmail.com

2. Discente do curso de Psicologia da UNIVILLE, Joinville, SC, Brasil. ORCID: 0000-0002-6353-5446 E-mail: mendes.laurasilva@gmail.com

3. Discente do curso de Psicologia da UNIVILLE, Joinville, SC, Brasil. ORCID: 0000-0002-6408-7358 E-mail: layenne.prado@gmail.com 4. Médico. Mestre em Neurociência. Docente do curso de graduação de Psicologia e Farmácia da UNIVILLE, Joinville/SC, Brasil. ORCID: 0000-0003-2636-7524 E-mail: rangel7@uol.com.br 


\section{INTRODUÇÃO}

$\mathbf{0}$ processo de despatologização da transexualidade, compreendida como um sentimento de não pertencimento ao sexo biológico ${ }^{1}$, e da homossexualidade, que compreende indivíduos que possuem atração por pessoas do mesmo sexo ${ }^{2}$, vem sendo assunto de muitas discussões da área da saúde nos últimos anos.

No período de 2009, houve em vinte e nove cidades, de diferentes países, um movimento para a retirada da temática de transtornos de identidade de gênero dos manuais de diagnóstico, como o Manual de Diagnóstico e Estatístico de Transtornos Mentais (DSM) e a Classificação Estatística Internacional de Doenças e Problemas Relacionados com a Saúde (CID) $)^{3,4}$.

Movimentos buscando a discussão sobre as temáticas relacionadas ao gênero e as problematizações acerca da patologização encontram-se em pauta desde 1950, quando surgiram os primeiros artigos sobre o transexualismo ${ }^{5}$.

Muito frequentes nos debates sobre a temática na época, identificou-se em estudos de endocrinologia artigos cujas características presentes nos indivíduos compreendidos como transexuais, seriam a abjeção desses por suas genitálias, entre outras ${ }^{5}$. Essa compreensão estava atrelada a critérios elaborados sobre o questionamento acerca do que tornava possível diagnosticar "o verdadeiro transexual”, no livro de 1966 intitulado "O fenômeno transexual"5.

Na maioria dos estudos, sem a utilização de suporte bibliográfico anterior, culminando numa inespecificidade do termo, originandose assim descrições sobre o fenômeno. Mesmo com o passar de décadas, os pontos levantados por ele são análogos aos de hoje, como tentativas de se vestir como o sexo oposto e culpa 6 .

Assim, a presente pesquisa tem como objetivo identificar discursos referentes à despatologização da homossexualidade e da transexualidade presentes na produção acadêmica e os posicionamentos técnicocientíficos de diversas áreas do conhecimento.

\section{MÉTODO}

Foi utilizado para esta revisão o método integrativo, que se caracteriza por uma abordagem que permite a inclusão de estudos experimentais e não-experimentais para uma compreensão do fenômeno analisado ${ }^{7}$. Para isso foram utilizadas as bases de dados SciELO, Scopus, PePSIC e Google Acadêmico.

Como critérios de inclusão para formação do corpus a ser analisado, foram utilizados somente artigos e teses publicados no período de 2000 a 2017, a partir dos descritores: patologia, transexualidade $\mathrm{e}$ homossexualidade, encontrados no título e nos resumos. 0 período de verificação do material utilizado iniciou-se no segundo semestre de 2017, estendendo-se até fevereiro de 2018.

Escolheram-se os artigos que estavam de acordo com o critério de inclusão em dois momentos. No primeiro, uma análise do resumo dos mesmos e, no segundo momento, fichamentos buscando as informações que se apresentassem mais relevantes, com dados recentes e que demonstrassem afinidade com a temática. Após tal processo de verificação, os dados pertinentes e relevantes de cada artigo, como questão histórica, legislação, questões biológicas e sociais da temática, foram coletados para a construção do presente artigo.

Para este trabalho, foram selecionados quatro autores de referência, Pierre-Henri Castel $^{1}$ e Georges Canguilhem ${ }^{8}$, que iniciaram as discussões sobre o tema pelo mundo e em vários idiomas. Além deles, também foram consultados os trabalhos de Berenice Bento $^{3,5,9,10}$ e Márcia Arán ${ }^{11-13}$, duas autoras brasileiras que seguem seus estudos utilizando as informações dos dois primeiros.

\section{RESULTADOS}

A partir do levantamento destes 30 artigos, considerou-se pertinente uma apresentação sucinta dos autores, títulos e objetivos específicos. O Quadro 1 torna possível uma visualização mais ampla daquilo que é discutido dentro da temática do presente artigo.

Tendo como base o Quadro 1, é possível identificar aspectos similares entres os trabalhos, como o período de pesquisa e 
publicação dos dados, os quais se encontram na última década. Dessa forma, é possível perceber que o tema é atual e possui relevância social. Percebe-se que, a partir do ano de 2009, tem-se um aumento na produção sobre a temática, totalizando 30 produções (entre artigos, teses e dissertações).

Quadro 1. Publicações sobre homossexualidade e transexualidade analisadas segundo autores, ano, título e síntese da abordagem apresentada entre 2000 a 2017. Joinville, SC, 2018

\begin{tabular}{|c|c|c|c|}
\hline $\begin{array}{l}\text { Autores e } \\
\text { Ano }\end{array}$ & $\begin{array}{c}\text { Modalidade } \\
\text { de } \\
\text { Publicação }\end{array}$ & Título & Questão da homossexualidade e ou transexualidade \\
\hline $\begin{array}{l}\text { Moreira MA, } \\
\text { Gomes AJM } \\
2017^{14}\end{array}$ & Artigo & $\begin{array}{l}\text { Representação social de } \\
\text { sexo e gênero entre } \\
\text { pessoas trans }\end{array}$ & $\begin{array}{l}\text { Aborda a temática de gênero e sexo, além da questâ } \\
\text { biológica e a concepção social. }\end{array}$ \\
\hline $\begin{array}{c}\text { Santos D, } \\
\text { Santos DSSD, } \\
\text { Dantas IDS, } \\
\text { Amaral AMS, } \\
\text { Paes HCDS } \\
2017^{15}\end{array}$ & Artigo & $\begin{array}{l}\text { Adolescência, Gênero e } \\
\text { Sexualidade: Uma revisão } \\
\text { Integrativa }\end{array}$ & $\begin{array}{l}\text { Traz sobre adolescência, sexualidade, construção social e } \\
\text { gênero. Abordando o que torna homem ou mulher, a } \\
\text { vulnerabilidade dos gêneros, compreensão da sexualidade } \\
\text { na adolescência e o papel do ambiente escolar na } \\
\text { identidade de gênero. }\end{array}$ \\
\hline $\begin{array}{c}\text { Costa AB, } \\
\text { Nardi HC, } \\
\text { Koller SH. } \\
201716 \\
\end{array}$ & Artigo & $\begin{array}{|ll|}\text { Manutenção } & \text { de } \\
\text { desigualdades } & \text { na } \\
\text { avaliação do gênero na } \\
\text { psicologia brasileira } & \\
\end{array}$ & $\begin{array}{l}\text { Apresenta a parte histórica que antecede o surgimento d } \\
\text { psicologia como ciência e posterior a ela, atrelando } \\
\text { discussão com a questão de gênero. }\end{array}$ \\
\hline $\begin{array}{l}\text { Venâncio } \\
\text { ATA, } \\
\text { Belmonte PR. } \\
2017^{17}\end{array}$ & Artigo & $\begin{array}{l}\text { Debate legislativo carioca } \\
\text { sobre a "mudança da } \\
\text { homossexualidade": } \\
\text { ciência, política e religião }\end{array}$ & $\begin{array}{l}\text { Debate acerca do projeto de lei } \mathrm{n}^{\circ} 717 / 03 \text {, que pretende } \\
\text { criar na cidade do Rio de Janeiro um programa que auxilie } \\
\text { aqueles que voluntariamente optarem pela mudança da } \\
\text { homossexualidade. Além de trazer um recorte histórico da } \\
\text { visão patológica acerca da homossexualidade. }\end{array}$ \\
\hline $\begin{array}{l}\text { Rocon PC, } \\
\text { Zamboni J, } \\
\text { Sodré F, } \\
\text { Rodrigues A, } \\
\text { Roseiro } \\
\text { MCFB. } \\
2017^{18}\end{array}$ & Artigo & $\begin{array}{l}\text { (Trans)formações } \\
\text { corporais: reflexões } \\
\text { sobre saúde e beleza }\end{array}$ & $\begin{array}{l}\text { Discute sobre saúde, beleza e adoecimento no meio } \\
\text { vivenciado pelos transexuais em processo de } \\
\text { transformação. Abordou questões dentro do campo da } \\
\text { beleza, como ideal de mulher, a dor associada à busca } \\
\text { desse ideal e os riscos possíveis. Já na questão de saúde e } \\
\text { doença, descreve o uso de hormônios e as cirurgias. }\end{array}$ \\
\hline $\begin{array}{c}\text { Raimondi GA, } \\
\text { Borges PD, } \\
\text { Bonsucesso } \\
\text { TF. } \\
2016^{19}\end{array}$ & Artigo & $\begin{array}{|lr|}\text { que } & \text { importa? } \\
\text { Pesquisas } & \text { Brasileiras no } \\
\text { Campo da Saúde e as (In) } \\
\text { visibilidades } \quad \text { das } \\
\text { Travestis e Transexuais }\end{array}$ & $\begin{array}{l}\text { Contextualiza a comunidade LGBT e as conquistas dentr } \\
\text { do Sistema Único de Saúde (SUS) e Conselho Federal d } \\
\text { Medicina. Além de trazer uma revisão bibliográfica focad } \\
\text { em travestis e transexuais e as seguintes temáticas } \\
\text { modificações corporais, estigmatização, HIV/AIDS e } \\
\text { patologização. }\end{array}$ \\
\hline $\begin{array}{l}\text { Borba R. } \\
2016^{20}\end{array}$ & Artigo & $\begin{array}{l}\text { Receita para se tornar um } \\
\text { "Transexual Verdadeiro" }\end{array}$ & $\begin{array}{l}\text { Recorte do caminho que um transexual percorre pelo SUS, } \\
\text { salientando e problematizando a necessidade do } \\
\text { diagnóstico. Discorre também sobre a patologização feita } \\
\text { pelo DSM, CID e CFM. }\end{array}$ \\
\hline $\begin{array}{l}\text { Oakley A. } \\
2016^{21}\end{array}$ & Artigo & A "Sexo e Gênero" & $\begin{array}{l}\text { Define sexo e gênero e os discute de modo sociocultural. } \\
\text { Traz o estudo realizado por Stoller, um psicólogo } \\
\text { especializado em distúrbios de identidade de gênero, } \\
\text { debatendo, assim, a diferença entre os casos apresentados, } \\
\text { de modo cultural e biológico. }\end{array}$ \\
\hline $\begin{array}{c}\text { Sposito SE. } \\
2015^{22}\end{array}$ & $\begin{array}{c}\text { Tese de } \\
\text { Doutorado }\end{array}$ & 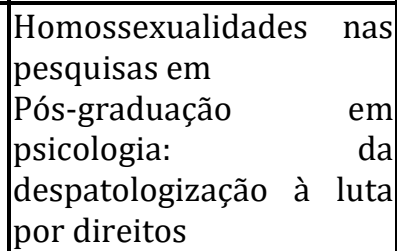 & $\begin{array}{l}\text { Sintetiza as produções em psicologia sobre a temática da } \\
\text { homossexualidade nos anos de } 1999 \text { até } 2010 \text {, trazendo a } \\
\text { contextualização da temática. Discute sobre gênero e o } \\
\text { processo de despatologização, com o posicionamento tido } \\
\text { pelo Conselho Federal de Psicologia. }\end{array}$ \\
\hline
\end{tabular}




\begin{tabular}{|c|c|c|c|}
\hline $\begin{array}{l}\text { Carneiro AJS } \\
2015^{23}\end{array}$ & Dissertação & $\left|\begin{array}{lr}\text { A morte da rínica: } \\
\text { movimento homossexual } \\
\text { e } \quad \text { luta } & \text { pela } \\
\text { despatologização } & \text { da } \\
\text { homossexualidade } & \text { no } \\
\text { Brasil (1978-1990). }\end{array}\right|$ & $\begin{array}{l}\text { Faz um recorte da história brasileira desde o Golpe civil- } \\
\text { militar de } 1964 \text { entrelaçado à homossexualidade e à } \\
\text { patologização da temática. Traz a visão da OMS, DSM e CID. } \\
\text { a Juntamente a isso, a luta contra a patologização de dois } \\
\text { focados grupos: Grupo Somos-SP e do Grupo Gay da Bahia. }\end{array}$ \\
\hline $\begin{array}{l}\text { Magalhães JC, } \\
\text { Ribeiro PRC. } \\
2015^{24}\end{array}$ & Artigo & $\begin{array}{|lr|}\text { Esquadrinhando } & \text { corpos } \\
\text { abjetos: ras } & \text { as } \\
\text { homossexualidades } & \text { nas } \\
\text { redes de enunciações } \\
\text { científicas }\end{array}$ & $\begin{array}{l}\text { S Inicia discorrendo sobre as identidades sexuais e } \\
\text { s sexualidade ao longo da história e, posteriormente, sobr } \\
\text { s a homossexualidade. } \\
\text { s }\end{array}$ \\
\hline $\begin{array}{l}\text { Almeida G, } \\
\text { Murta D. } \\
2013^{25}\end{array}$ & Artigo & 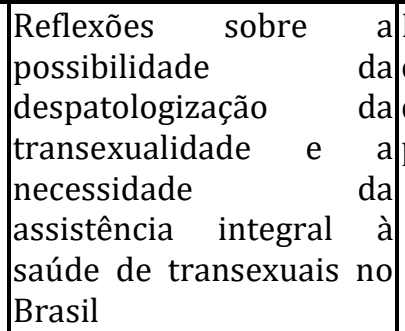 & $\begin{array}{l}\text { Discute sobre a transexualidade como um dos campos c } \\
\text { estudo dentro das questões de gênero, além } \\
\text { desenvolver a construção da temática dentro do quadro c } \\
\text { patologia e a questão social dela oriunda. } \\
\text { a }\end{array}$ \\
\hline $\begin{array}{l}\text { Santos DK } \\
2013^{26}\end{array}$ & Artigo & 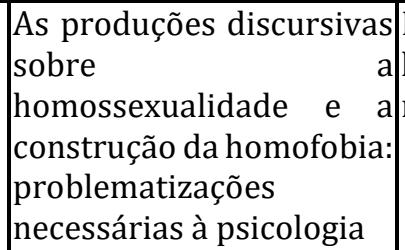 & $\begin{array}{l}\text { Problematiza temáticas dentro do campo da } \\
\text { homossexualidade como homofobia, patologização e } \\
\text { medicalização. }\end{array}$ \\
\hline $\begin{array}{l}\text { Bento B. } \\
2012^{5}\end{array}$ & Artigo & \begin{tabular}{|l|} 
Despatologização do \\
gênero: a politização das \\
identidades abjetas
\end{tabular} & $\begin{array}{l}\text { Reconstrói o processo do gênero como uma categoria } \\
\text { diagnóstica, além do processo para a retirada da } \\
\text { patologização e das estratégias utilizadas na campanha. }\end{array}$ \\
\hline \begin{tabular}{|c|} 
Andreazza TS. \\
$2012^{27}$
\end{tabular} & Artigo & $\begin{array}{|lr|}\text { Gêmeos monozigóticos } \\
\text { discordantes } & \text { para } \\
\text { transexualidade: } & \\
\text { diferenças } & \\
\text { neuroanatômicas } & \text { e } \\
\text { psicológicas. } & \end{array}$ & $\begin{array}{l}\text { Introduz uma definição da transexualidade, versando } \\
\text { sobre os fatores genéticos, hormonais, ambientais, } \\
\text { neuroanatômicos e cognitivos na transexualidade. }\end{array}$ \\
\hline $\begin{array}{l}\text { Spizzirri G } \\
2012^{28}\end{array}$ & Artigo & \begin{tabular}{|l|} 
Transexualismo \\
neuroimagem
\end{tabular} & $\begin{array}{l}\text { Traz um panorama sobre a transexualidade no CID-10 e } \\
\text { DSM IV. Discute também a questão de gênero atrelada à } \\
\text { genética. }\end{array}$ \\
\hline $\begin{array}{c}\text { Ceccarelli PR. } \\
2012^{29}\end{array}$ & Artigo & $\begin{array}{lc}\text { A } & \text { invenção } \\
\text { homossexualidade }\end{array}$ & $\begin{array}{l}\text { Debate sobre a criação das categorias de nomenclatura, } \\
\text { contextualizando a partir de um olhar fenomenológico. } \\
\text { Aborda o tema, também, pela perspectiva psicanalítica, } \\
\text { tanto de Freud como dos pós-freudianos, finalizando com } \\
\text { o olhar atual. }\end{array}$ \\
\hline $\begin{array}{l}\text { Balestero GS } \\
2011^{2}\end{array}$ & Artigo & 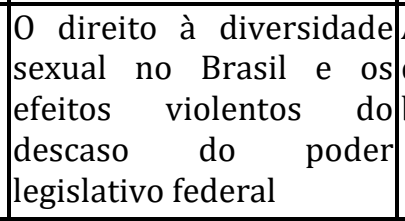 & $\begin{array}{l}\text { Aborda desde o conceito da homossexualidade até o } \\
\text { s debate social acerca da homofobia, como estatísticas } \\
\text { brasileiras e os projetos governamentais nessa temática. } \\
\text { brato }\end{array}$ \\
\hline $\begin{array}{l}\text { Bento B. } \\
2011^{3}\end{array}$ & Artigo & $\begin{array}{l}\text { Luta Globalizada pelo fim } \\
\text { do diagnóstico de gênero }\end{array}$ & $\begin{array}{l}\text { Retoma a tentativa de organizações voltadas ao } \\
\text { engajamento pela retirada da transexualidade do DSM e do } \\
\text { CID. Demonstra os critérios e visões sobre essa questão de } \\
\text { gênero dentro do CID } 10 \text { e DSM IV. }\end{array}$ \\
\hline $\begin{array}{l}\text { Athayde AVL. } \\
2011^{6}\end{array}$ & Artigo & $\begin{array}{l}\text { Transexualismo } \\
\text { Masculino }\end{array}$ & $\begin{array}{l}\text { Compilado de informações sobre o histórico da } \\
\text { transexualidade, a questão das nomenclaturas, a } \\
\text { associação com as doenças psiquiátricas, prevalência, } \\
\text { diagnóstico, etiologia, tratamento, cirurgia e suas } \\
\text { complicações. }\end{array}$ \\
\hline
\end{tabular}




\begin{tabular}{|c|c|c|c|}
\hline $\begin{array}{l}\text { Langdon EJ, } \\
\text { Wiik FB. } \\
2010^{30}\end{array}$ & Artigo & $\begin{array}{l}\text { Antropologia, saúde e } \\
\text { doença: uma introdução } \\
\text { ao conceito de cultura } \\
\text { aplicado às ciências da } \\
\text { saúde }\end{array}$ & $\begin{array}{l}\text { Discute o significado de cultura e os aspectos atrelados, } \\
\text { podendo abordar e discutir sobre saúde e doença, } \\
\text { mostrando como as três temáticas se entrelaçam. }\end{array}$ \\
\hline $\begin{array}{l}\text { Butler J } \\
2009^{4}\end{array}$ & Artigo & $\begin{array}{l}\text { Desdiagnosticando } \\
\text { gênero }\end{array}$ & $\begin{array}{l}\text { Conduz o debate em duas frentes. Por um lado, a que não } \\
\text { concorda com o diagnóstico de transtorno de identidade } \\
\text { de gênero feito pelo DSM IV. Por outro, mostra a } \\
\text { preferência, por alguns, da permanência do diagnóstico } \\
\text { como um facilitador para recursos médicos para a } \\
\text { transição. Traz, ainda, um recorte histórico para que as } \\
\text { duas posições possam ser compreendidas. }\end{array}$ \\
\hline $\begin{array}{c}\text { Franco FLFN } \\
2009^{8}\end{array}$ & Artigo & $\begin{array}{l}\text { Georges Canguilhem e a } \\
\text { psiquiatria: norma, saúde } \\
\text { e patologia mental }\end{array}$ & $\begin{array}{l}\text { Canguilhem realiza suas pesquisas no âmbito da } \\
\text { psiquiatria e, assim, ressalta a relevância das patologias } \\
\text { mentais, assim como discute o que é saúde, normalidade e } \\
\text { doença. Para o autor, trata-se de um debate necessário. }\end{array}$ \\
\hline $\begin{array}{l}\text { Arán M, Murta } \\
\text { D, Lionço T. } \\
2009^{12}\end{array}$ & Artigo & $\begin{array}{l}\text { Transexualidade e saúde } \\
\text { pública no Brasil. Ciência } \\
\text { \& saúde coletiva }\end{array}$ & $\begin{array}{l}\text { Introduz as noções do Conselho Federal de Medicina e o } \\
\text { processo de autorização e realização das cirurgias de } \\
\text { transgenitalização, bem como todas as etapas necessárias } \\
\text { para que sejam feitas por meio do sistema único de saúde. } \\
\text { Completa com uma retomada histórica da visão da } \\
\text { psiquiatria sobre a transexualidade. }\end{array}$ \\
\hline $\begin{array}{c}\text { Arán M, Murta } \\
\text { D. } \\
200913\end{array}$ & Artigo & $\begin{array}{|lr|}\text { Do } & \text { diagnóstico } \\
\text { transtorno de identidade } \\
\text { de gênero às redescrições } \\
\text { da } \quad \text { experiência } \\
\text { transexualidade: } \\
\text { reflexão sobre } \\
\text { tecnologia e saúde }\end{array}$ & $\begin{array}{l}\text { Analisa as dificuldades dentro das políticas públicas, } \\
\text { focando na necessidade do diagnóstico de Transtorno de } \\
\text { Identidade de Gênero como porta de acesso. Aborda, } \\
\text { também, o tratamento hormonal, as cirurgias disponíveis } \\
\text { e o Transtorno de Identidade de Gênero. }\end{array}$ \\
\hline $\begin{array}{c}\text { Calçado T. } \\
2009^{31}\end{array}$ & $\begin{array}{l}\text { Tese de } \\
\text { Mestrado }\end{array}$ & $\begin{array}{l}\text { Doença: sofrimento e vida } \\
\text { nas filosofias de Friedrich } \\
\text { Nietzsche e Blaise Pascal }\end{array}$ & $\begin{array}{l}\text { Discute a compreensão de doença tanto para Nietzsche } \\
\text { quanto para Pascal. }\end{array}$ \\
\hline $\begin{array}{l}\text { Carneiro AJS } \\
2007^{32}\end{array}$ & Artigo & $\begin{array}{|llr|}\text { Homofobia: limites } & \text { e } \\
\text { possibilidades de um } \\
\text { conceito em meio a } \\
\text { disputas }\end{array}$ & $\begin{array}{l}\text { Discute sobre o fenômeno da homofobia, desde o conceito } \\
\text { até as consequências acarretadas. }\end{array}$ \\
\hline $\begin{array}{c}\text { Matias D. } \\
200733\end{array}$ & Artigo & $\begin{array}{l}\text { Psicologia e orientação } \\
\text { sexual: Realidades em } \\
\text { transformação }\end{array}$ & $\begin{array}{l}\text { Avalia o posicionamento da Associação Psiquiátrica } \\
\text { Americana sobre a homossexualidade e debate a temática } \\
\text { pelo viés cultural atual. }\end{array}$ \\
\hline $\begin{array}{l}\text { Arán M. } \\
2006^{11}\end{array}$ & Artigo & $\begin{array}{l}\text { Transexualidade e a } \\
\text { gramática normativa do } \\
\text { sistema } \\
\text { sexo-gênero }\end{array}$ & $\begin{array}{l}\text { Objetiva debater a transexualidade dentro do âmbito da } \\
\text { psiquiatria e da psicanálise, contextualizando a temática, } \\
\text { versando sobre o transtorno de identidade de gênero e sua } \\
\text { parte histórica. Além de combinar a temática com a visão } \\
\text { atual. }\end{array}$ \\
\hline $\begin{array}{l}\text { Bento B. } \\
2003^{10}\end{array}$ & Artigo & $\begin{array}{l}\text { Transexuais, corpos e } \\
\text { próteses }\end{array}$ & $\begin{array}{l}\text { Debate sobre o gênero e as atribuições feitas a cada um. } \\
\text { Posteriormente, discute sobre a cirurgia de } \\
\text { transgenitalização e sexualidade. }\end{array}$ \\
\hline
\end{tabular}

\section{DISCUSSÃO}

As produções levantadas abordam questões de gênero, discorrendo sobre o viés de normalidade e patologia, dentro dessa dualidade e as repercussões acarretadas.

De tal modo, já não há mais uma soberania de ideias essencialistas e/ou biologizantes naquilo que toca os estudos a respeito da homossexualidade. Entende-se que as perspectivas socioconstrutivistas, construcionistas e sócio-históricas, juntamente com as contribuições de Focault, possibilitam um panorama predominante nessa área, dentro da psicologia.

Sendo assim, é possível contemplar a diversidade de caminhos pelos quais se busca defender um determinado posicionamento. Tal tarefa representa um desafio 
independentemente das bases teóricas escolhidas para tanto, tendo em vista a complexidade da temática discutida que não pode ser abordada de forma simplista ou unidimensional, por se tratar da singularidade humana.

Sendo assim, durante a análise dos
dados, identificou-se que tais
posicionamentos estão atrelados a uma mudança de olhar, mudando a perspectiva mais biológica, presente nos primeiros $\operatorname{artigos}^{10,11 \text {. }}$

A partir de 20094,12,22, nota-se uma mudança de perspectiva, quando se começa a discutir a questão de gênero também associada às questões subjetivas e sociais, relacionadas à saúde pública e à despatologização.

Até o presente momento, há pouca concordância sobre o que determina ou não a própria concepção de indivíduo patológico ou saudável ${ }^{31}$. Essa concepção está subordinada a elementos de ordem maior, tais como a cultura na qual um indivíduo está inserido ${ }^{30}$, as determinações a respeito da sexualidade, entre outros. Pode-se considerar essa multiplicidade de perspectivas como um alerta frente às tentativas de classificação realizadas dentro das ciências humanas e das ciências biológicas.

Uma das discussões levantadas diz respeito aos fatores genéticos ${ }^{27}$, que podem estar atrelados à determinação de tais identidades, entretanto, não há evidências suficientes e correlações que justifiquem tal ponto de vista, já que mesmo que estudos preliminares demonstrem uma variação genética específica em transexuais ${ }^{5}$, isso configura um problema do ponto de vista de critérios diagnósticos, visto que a visão biológica é um dos pilares da medicina contemporânea.

É possível afirmar que existe influência cultural sobre as identidades sexuais, uma vez que elas são incorporadas pelas representações sociais que os sujeitos têm de si mesmos e as significações que a sociedade elabora no seu cotidiano ${ }^{14}$. Tal como quando se discute sobre os padrões culturais impostos pela sociedade, os quais ditam o que é normal e adequado para o sexo feminino e masculino.
Quando se argumenta sobre atividades do sexo masculino, vinculam-se questões voltadas à força física, tomadas de decisão e racionalidade, prover alimento e proteção para a família e a paternidade entrelaçada, além da virilidade e incapacidade de controle dos desejos sexuais. Já as atividades vinculadas ao sexo feminino encontram-se no âmbito da beleza, sensualidade, docilidade, subordinação ao homem e associada à família, como a ideia de maternidade ${ }^{15}$.

Logo, vendo-se a constituição social dessas identidades pré-concebidas socialmente como um dos propulsores de tais incompreensões e catalogações patológicas, pode-se considerar o próprio meio social como uma das possibilidades de intervenção prática e de modificação dessa opressão em algo além da tolerância, em uma luta pela aceitação da categoria transgênero que surge como alternativa ao antigo modelo médico, na tentativa de afirmar as variações de gênero como variações da normalidade. Essa nova visão sobre o gênero une as bandeiras dos movimentos sociais, ampliando o foco da luta pela construção da igualdade de gênero entre mulheres e homens, na direção da igualdade entre pessoas cis e trans ${ }^{16}$.

Refletindo sobre a temática, pode-se ter outros olhares como o da psicanálise, que compreende que a sexualidade e, principalmente, a diferença sexual, são fenômenos complexos que definem formas de manifestação das subjetividades ${ }^{11}$. Estudiosos dessa perspectiva argumentam que essa desordem ocorre a partir da constituição do self que se encontra afetado ${ }^{6}$.

0 teórico psicanalítico de maior contribuição neste âmbito foi Lacan, que argumenta que a compreensão do ser pela psiquiatria ocorria pela psicose, ou seja, estaria fundado na convicção de alterações relacionadas à identidade e ao desejo incontrolável pela mudança de sexo. Neste sentido, não tendo o Édipo, o recalque e a falta como operadores organizativos, o transexualismo seria uma forma específica de psicose ${ }^{11}$.

Outro olhar sobre a temática, não centrado em uma única linha de pensamento teórica, é o do Sistema Único de Saúde (SUS), 
que disponibiliza acesso a essa população, de forma gratuita e, por conseguinte, a patologização da transexualidade não garantiu direitos de fato, mas estabeleceu que a mesma pode ser vista como uma experiência catalogável, curável e por isso, passível de normalização ${ }^{3}$.

Ainda hoje, no SUS, sistema destinado a todos, há dificuldades de acesso para alguns homens e mulheres transexuais. Assim, a esfera pública não tem sido uma boa alternativa ${ }^{25}$.

No livro "Reinvenção do corpo: sexualidade e gênero na experiência transexual" é apresentado como principal forma de "diagnóstico" do "transexualismo" o relato do próprio sujeito, enfatizando a relação com as fases iniciais do seu desenvolvimento ${ }^{9}$. Esse relato deve ser coerente com a solicitação atual do indivíduo, de modo que fique clara sua repulsa por sua genitália, e não apenas um desconforto ao se sentir obrigado a utilizar determinadas vestimentas, conforme o que a sociedade afirma ser o correto.

Partindo-se disso, a nomenclatura de transexualidade foi incluída no Manual de Diagnóstico Estatístico de Transtornos Mentais (DSM III), na década de 19806,23. Trata-se de um documento da Associação Psiquiátrica Norte Americana (APA), que teve sua primeira versão publicada no ano de $1952^{3}$, e que poucas décadas depois incluiu o conceito em seus diagnósticos.

Análoga a essa discussão, há a questão do homossexualismo, que em 1973 foi retirado do DSM pela APA e, alguns anos depois, em 1990, foi excluído do Código Internacional de Doenças (CID) pela Organização Mundial da Saúde ${ }^{32,17,32}$.

Além disso, desde 1999, o Conselho Federal de Psicologia compreende que nenhum profissional pode atuar de modo que estabeleça e favoreça um viés favorável à patologização de comportamentos ou de práticas homoeróticas ${ }^{34}$.

A transsexualidade e a homossexualidade ainda consistem em discussões cercadas de dúvidas e tabus, gerando uma rede de preconceito e desinformação.
Dentre os motivos que resultaram na atual concepção patológica dessas identidades sexuais e na inclusão delas em categorias diagnósticas, pode-se mencionar os estudos realizados para investigar a neurobiologia de transexuais, dentro dos quais foram encontradas algumas diferenças de caráter estrutural no encéfalo de pessoas que se identificam como transexuais, quando comparadas com sujeitos heterossexuais controle ${ }^{28}$.

Além disso, é possível observar posicionamentos pautados no essencialismo biológico entre algumas pessoas transexuais, como a ideia de incompletude de um (a) homem/mulher até o momento em que a cirurgia, conhecida com, transgenitalização seja feita, mesmo que o indivíduo já seja reconhecido socialmente na sua identidade ${ }^{25}$. Tal fenômeno pode ser atrelado a distinções que vão além de aspectos ligados à psique, ou mesmo, de critérios patológicos.

Desde 2003, no Brasil, foram encontrados diversos estudos dentro dos campos da psicologia, serviço social e saúde coletiva com o propósito de conhecer como ocorrem as vivências e os cuidados especializados durante a realização da cirurgia de transgenitalização ${ }^{28-36}$. Esse diagnóstico é de extrema importância, pois com ele, no Brasil, a pessoa pode ter acesso aos tratamentos hormonais e até mesmo à cirurgia de redesignação sexual, conhecido no senso comum como cirurgia para mudança de sexo $^{29}$, pagos pelo poder público, por meio do SUS. Isso é possível desde $2008^{30,31}$.

0 termo homossexualidade foi cunhado em 1869, primeiramente por um estudioso da área da medicina, a partir das seguintes raízes: "homo, que significa semelhante, e pela palavra sexus, significando, portanto, o termo 'sexualidade semelhante'”. Ademais, outra concepção compreende a homossexualidade como a situação no qual um indivíduo possui sentimentos, de forma romântica, por alguém do mesmo sexo. Salienta-se, ainda, que isso não representa nenhum desvio psicológico ou do gênero ${ }^{2}$. Portanto, nos dias atuais se proscreve o sufixo "ismo", já que ele indica um olhar voltado para o patológico ${ }^{37}$.

Postula-se que a homossexualidade, 
bem como a heterossexualidade e a bissexualidade, é um produto da sociedade em que se vive, muitas vezes compreendido como verdade inata, e que na atual situação vivida a heterossexualidade é a dita predominante e está enraizada no imaginário como a correta, fazendo com que tudo o que é diferente seja colocado como desviante, gerando assim o preconceito ${ }^{35}$.

Os corpos dos sujeitos que se identificam como homossexuais são tomados como diferentes pelas "tecnologias empregadas na observação dos corpos e na produção de saberes", ou seja, eles se diferem do que se tem como desenvolvimento "normal" da orientação sexual, aqui visto como a heterossexualidade, o que prende as identidades sexuais a destinações biológicas ${ }^{24}$.

No que diz respeito à identificação da transexualidade, pode-se tomar como conceito geral aquilo que defende o artigo intitulado "algumas reflexões para estabelecer a cronologia do 'fenômeno transexual' (19101995)"1, no qual se estabelece que a transexualidade "caracteriza-se pelo sentimento intenso de não-pertencimento ao sexo anatômico, sem a manifestação de distúrbios delirantes e sem bases orgânicas (como o hermafroditismo ou qualquer outra anomalia endócrina) ${ }^{11 " .}$.

Em um recorte histórico concernente ao "transexualismo" é interessante mencionar que foi estabelecida uma relação entre o mesmo e a endocrinologia. Apoiado nos avanços dos estudos biológicos do século XX, em especial os estudos genéticos, propõe-se que não haveria uma divisão absoluta entre "masculino" e "feminino", sendo inadequada a determinação do sexo do indivíduo com base exclusivamente nas diferenças anatômicas. Para ele, o sexo é composto por diversos componentes, de modo que a etiologia do transexualismo e a origem do desejo de mudar de sexo ultrapassam os aspectos psicológicos, podendo estar associadas a causas biológicas - genéticas ou endócrinas ${ }^{12}$.

Predisposições genéticas, influências psicossociais e ambientais, bem como a exposição a hormônios, estão ligadas, mesmo que parcialmente, ao processo de desenvolvimento do gênero dos indivíduos ${ }^{28}$.

No entanto, destaca-se que estudos recentes evidenciam que a associação entre disfunções hormonais e a transexualidade não se sustenta, visto que o número de indivíduos com essas alterações e os índices de transexualidade nos mesmos têm baixa correlação, o que revela uma influência não determinante entre identidade sexual e fatores endócrinos ${ }^{27}$.

É baseada nesses fatores de ordem biológica, que está sustentada a atual concepção patologizante dessas identidades sexuais. Para tanto, é necessário compreender o conceito de patologia. Segundo o Dicionário Aurélio de Língua Portuguesa, trata-se de um "desvio em relação ao que é considerado normal do ponto de vista fisiológico $e$ anatômico e que constitui ou caracteriza uma doença"38.

Quanto aos limites que permeiam os estados de "Normalidade" ou "Patologia", é pertinente mencionar algumas reflexões. A doença singulariza, individualiza. Por essa razão, cabe ao próprio ser vivo individual (não ao ser vivo que sofre atualmente, mas a uma experiência subjetiva que orienta a constituição do olhar clínico) a responsabilidade de distinguir o ponto em que começa a doença. Sendo assim, a noção de normal não pode derivar de uma média estatística e, tampouco, de um tipo ideal ${ }^{8}$.

Nesse sentido, recorre-se às reflexões propostas por Thiago Calçado a partir de uma releitura de Foucault, que diz que "o diagnóstico é um poder reservado ao médico que se pronuncia sobre o enfermo e sua enfermidade. 0 doente que se enquadra nessa dinâmica da clínica se reduz, se instaura pelo saber médico e abstém-se de prognosticar sobre si e sobre sua saúde"31.

Afirma-se que há diferenças entre o que a medicina compreende sobre a transexualidade e o corpo e o que os próprios indivíduos que se identificam como tal sentem ${ }^{18}$.

0 modelo biomédico, ao se orientar por variáveis anatômicas, fisiológicas e psicopatológicas engendradas pelas normas binárias de gênero, segue patologizando e medicalizando os corpos e as experiências 
transexuais. Por outro lado, avaliações realizadas por pessoas transexuais parecem seguir orientações distintas, pelas quais as transformações corporais constituem processos de produção de saúde, explorando a plasticidade de seus corpos como potência de vida, mediada pelos ideais de beleza.

Em conformidade, pode-se dizer que o termo "transexualismo" e sua compreensão como "transtorno de identidade" estão entrelaçados ao pensamento que compreende o sexo como algo estabelecido pela natureza, orgânico, genético e biológico. Além disso, o gênero é constituído pela cultura na qual está inserido. Sendo assim, essa visão compreende que o sexo, seja homem ou mulher, é algo natural, enquanto o gênero é uma construção histórico-social ${ }^{9,13}$.

Desse modo, entende-se que a identidade de gênero na qual um indivíduo se insere não está subordinada a fatores biológicos e inatos. Os papéis a serem desempenhados, do masculino ou do feminino, estão atrelados, na verdade, à subjetividade de cada indivíduo. Nesse ponto, a identidade de gênero deve ser plástica e se adequar à identidade com a qual cada indivíduo se estabelece ${ }^{21,39}$.

Assim, contemporaneamente, essa aparente concepção de "normalidade", saudável, não patológica, incide tão somente sobre os indivíduos de orientação heterossexual, única expressão sexual aceita como natural nos mais variados contextos sociais. As orientações sexuais que divergem dela são consideradas indesejáveis ou anormais ${ }^{22,33}$.

Toda ciência que visa discutir uma concepção da identidade humana deve ser cautelosa e levar em conta que ela é interativa e dinâmica, diferentemente das árvores, por exemplo, que não se importam em ser classificadas como tal. Quando as pessoas se tornam cientes da forma como são catalogadas, isso faz com que elas modifiquem a sua atuação, o que requer novas classificações, as quais gerarão novas formas do agir, num efeito retroalimentador ao longo da história do conhecimento ${ }^{16}$.

As concepções patologizantes da diversidade de identidades sexuais estão amparadas sobre padrões pré-estabelecidos que designam o "masculino" ou o "feminino", apresentando um constructo bipolar e unifatorial para tais padronizações, ou seja, elas se configuram como polos opostos de um único continuum, desconsiderando diversos fatores de ordem subjetiva, além da existência de muitos comportamentos que são indiferentes a ambos os sexos, intitulados andrógenos.

A concepção particular que cada um tem de si e a sua autodesignação refletem a liberdade almejada por cada sujeito na constituição de sua própria identidade, a qual se encontra além de padrões sancionados socialmente ou por uma comunidade científica externa.

\section{CONCLUSÃO}

Através desta revisão integrativa, foi possível verificar que o tema tratado é amplo e vem sendo base para análises e discussões de vários campos do conhecimento, com ênfase nos âmbitos social, biológico e psicológico ao longo dos anos. Isso apenas demonstra que homossexuais e transexuais vêm enfrentando uma série de classificações que divergem entre si e, por sua pluralidade, é provável que apenas uma ou mesmo nenhuma delas esteja "correta".

Ainda assim, mesmo que não exista um consenso preciso sobre os determinantes da transexualidade e da homossexualidade e seu questionável enquadre diagnóstico, foi possível alcançar o objetivo proposto. Identificaram-se e foram expostos diversos posicionamentos referentes a despatologização da homossexualidade e da transexualidade dentro de um âmbito técnicocientífico.

Notou-se limitações devido ao método utilizado, o qual não resultou na exaustão de todos os trabalhos elaborados ao longo do período de tempo estudado, uma vez que o estudo se ateve a algumas bases. Ademais, os idiomas utilizados (português e inglês), e a restrição a formas de acesso livre podem ser vistos como fatores limitantes. Por sua vez, verificou-se a amplitude do tema.

A temática carrega consigo diversas posições, o que demanda, portanto, futuras 
pesquisas e aprofundamentos. Recomenda-se a condução de novos estudos com investigações diferenciadas, para alcançar uma maior compreensão dos contextos nos quais os indivíduos homossexuais e transexuais estão inseridos.

\section{REFERÊNCIAS}

1. Castel PH. Algumas reflexões para estabelecer a cronologia do "fenômeno transexual" (19101995). Rev Bras Hist. [Internet]. 2001 [citado em 16 ago 2017]; 21(41):77-111. Disponível em:

http://www.scielo.br/pdf/rbh/v21n41/a05v2 141.pdf.

http://dx.doi.org/10.1590/S0102-

01882001000200005

2. Balestero GS. 0 direito à diversidade sexual no Brasil e os efeitos violentos do descaso do poder legislativo federal. Rev Espaço Acadêmico. [Internet]. 2011 [citado em 23 set 2017]; 11(123):05-16. Disponível em: http://periodicos.uem.br/ojs/index.php/Espac oAcademico/article/view/12331

3. Bento B. Luta globalizada pelo fim do diagnóstico de gênero? In: Santos LHS, Ribeiro PRC, organizadores. Corpo, gênero e sexualidade: instâncias e práticas de produção nas políticas da própria vida [Internet]. Rio Grande: FURG; 2011 [citado em 23 set 2017]. p. 89-108. Disponível em: https://seminariocorpogenerosexualidade.furg .br/images/documentos/5-Seminrio.pdf

4. Butler J. Desdiagnosticando o gênero. Physis. [Internet]. 2009 [citado em 22 set 2017]; 19 (1):95-126. Disponível em: http://www.scielo.br/pdf/physis/v19n1/v19n 1a06.pdf.

DOI:

http://dx.doi.org/10.1590/S01037331200900 0100006

5. Bento B, Pelucio L. Despatologização do gênero: a politização das identidades abjetas. Estud Fem. [Internet]. 2012 [citado em 26 set 2017]; 20(2):559-68. Disponível em: https://periodicos.ufsc.br/index.php/ref/articl e/view/S0104-026X2012000200017/22863.

DOI: $\quad$ http://dx.doi.org/10.1590/S0104026X2012000200017

6. Athayde AVL. Transexualismo masculino. Arq Bras Endocrinol Metabol. [Internet]. 2001 [citado em 22 set 2017]; 45(4): 407-14. Disponível em: http://www.scielo.br/pdf/abem/v45n4/a14v4 5n4.pdf

7. Souza MT, Silva MD, Carvalho R. Revisão integrativa: o que é e como fazer. Einstein. [Internet]. 2010 [citado em 29 set 2017]; 8(1 Pt 1):102-6. Disponível em: http://www.scielo.br/pdf/eins/v8n1/pt_16794508-eins-8-1-0102.pdf

8. Franco FLFN. Georges Canguilhem e a psiquiatria: norma, saúde e patologia mental. Prim Escritos. [Internet]. 2009 [citado em 22 set 2017]; 1(1):87-95. Disponível em: http://www.revistas.usp.br/primeirosescritos /article/view/136830/132577.

DOI:

http://dx.doi.org/10.11606/issn.2594-

5920.primeirosestudos.2009.136830

9. Bento B. A reinvenção do corpo: sexualidade e gênero na experiência transexual. Rio de Janeiro: Garamond; 2006. 256p.

10. Bento B. Transexuais, corpos e próteses. Labrys: Estud Fem. [Internet]. 2003 [citado em 15 out. 2017]; 4:1-13. Disponível em: https://gedsfdusp.files.wordpress.com/2015/0 8/06-bento-berenice-transexuais-corpos-eprc3b3teses.pdf

11. Arán M. A transexualidade e a gramática normativa do sistema sexo-gênero. Ágora. [Internet]. 2006 [citado em 15 out 2017]; 9(1):49-63. Disponível em: http://www.scielo.br/pdf/agora/v9n1/a04v9n 1.pdf. DOI: http://dx.doi.org/10.1590/S151614982006000100004

12. Arán M, Murta D, Lionço T. Transexualidade e saúde pública no Brasil. Ciênc Saúde Colet. [Internet]. 2009 [citado em 15 out 2017]; 14(4):1141-9. Disponível em: http://www.scielo.br/pdf/csc/v14n4/a15v14n 4.pdf. DOI: http://dx.doi.org/10.1590/S141381232009000400020

13. Arán M, Murta D. Do diagnóstico de transtorno de identidade de gênero às redescrições da experiência da transexualidade: uma reflexão sobre gênero, tecnologia e saúde. Physis. [Internet]. 2009 [citado em 22 out 2017]; 19(1):15-41. Disponível em: http://www.scielo.br/pdf/physis/v19n1/v19n 1a03.pdf DOI: http://dx.doi.org/10.1590/S01037331200900 100003

14. Moreira MA, Gomes AJM. Representações sociais de estudantes concluintes de enfermagem sobre transexualidade. Rev Enferm UFPE on line. [Internet] 2013. [citado em 22 out 2017]; 7(6):4378-88. Disponível em:

https://periodicos.ufpe.br/revistas/revistaenfe 
rmagem/article/viewFile/11677/1387

15. Santos D, Santos DSSD, Dantas IDS, Amaral AMS, Paes HCDS. Adolescência, gênero e sexualidade: uma revisão Integrativa. Rev Enferm Contemp. [Internet]. 2017 [citado em 22 out 2017]; 6(1):62-8. Disponível em: https://www5.bahiana.edu.br/index.php/enfe rmagem/article/view/1114.

https://doi.org/10.5205/1981-8963-

v7i6a11677p4378-4388-2013

16. Costa AB, Nardi HC, Koller SH. Manutenção de desigualdades na avaliação do gênero na psicologia brasileira. Temas Psicol. [Internet]. 2017 [citado em 22 out 2017]; 25(1):97-115. Disponível em: http://pepsic.bvsalud.org/pdf/tp/v25n1/v25n 1a06.pdf DOI: http://dx.doi.org/10.9788/TP2017.1-06

17. Venâncio ATA, Belmonte PR. Debate legislativo carioca sobre a "mudança da homossexualidade": ciência, política e religião. Rev Sex Salud Soc. [Internet]. 2017 [citado em 12 nov 2017]; 26:103-25. Disponível em: http://www.scielo.br/pdf/sess/n26/19846487-sess-26-00103.pdf http://dx.doi.org/10.1590/1984-

6487.sess.2017.26.06.a

18. Rocon PC, Zamboni J, Sodré F, Rodrigues A, Roseiro MCFB. (Trans)formações corporais: reflexões sobre saúde e beleza. Saúde Soc. [Internet]. 2017 [citado em 12 abr 2018]; 26(2): 521-32. Disponível em: http://www.scielo.br/pdf/sausoc/v26n2/1984 -0470-sausoc-26-02-00521.pdf http://dx.doi.org/10.1590/s010412902017171907

19. Raimondi GA, Borges PD, Bonsucesso TF. O que importa? As pesquisas brasileiras no campo da saúde e as (in) visibilidades das travestis e transexuais. Saúde Transform. Soc. [Internet]. 2016 [citado em 21 fev 2018]; 7(3):133-46. Disponível em: http://stat.elogo.incubadora.ufsc.br/index.php /saudeetransformacao/article/view/4197/465 4

20. Borba R. Receita para se tornar um "transexual verdadeiro": discurso, interação e (des)identificação no processo transexualizador. Trab Linguist Apl. [Internet]. 2016 [citado em 02 mar 2018]; 55(1):33-75. Disponível em: http://www.scielo.br/pdf/tla/v55n1/0103181 3-tla-55-01-00033.pdf DOI: http://dx.doi.org/10.1590/010318135029176

\section{1}

21. Oakley A. Sexo e gênero. Feminismos. [Internet]. 2016 [citado em 12 abr 2018]; 4(1):64-71. Disponível em: http://www.feminismos.neim.ufba.br/index.ph $\mathrm{p} / \mathrm{revista/article/view/393/216}$

22. Sposito SE. Homossexualidades nas pesquisas em pós-graduação em psicologia: da despatologização à luta por direitos. [Dissertação]. Assis, SP: Universidade Estadual Paulista/UNESP; 2015. 209p.

23. Carneiro AJS. A morte da clínica: movimento homossexual e luta pela despatologização da homossexualidade no Brasil (1978-1990). In: XXVIII Simpósio Nacional de História [Internet]; 2015; Florianópolis, SC. Florianópolis, SC: UFSC; 2015 [citado em: 08 abr 2019]. Disponível em: http://www.snh2015.anpuh.org/resources/an ais/39/1439866235_ARQUIVO_Artigo-

Amortedaclinica.pdf

24. Magalhães JC, Ribeiro PRC. Esquadrinhando corpos abjetos: as homossexualidades nas redes de enunciações científicas. Educ Pesqui. [Internet]. 2015 [citado em 22 mar 2018]; 41(Esp): 1553-68. Disponível em: http://www.revistas.usp.br/ep/article/view/1 09921/108417

https://dx.doi.org/10.1590/S1517-

9702201508142513

25. Almeida G, Murta D. Reflexões sobre a possibilidade da despatologização da transexualidade e a necessidade da assistência integral à saúde de transexuais no Brasil. Sex Salud Soc. [Internet] 2013 [citado em 22 out.2017]; 14:380-407. Disponível em: http://www.scielo.br/pdf/sess/n14/a17n14.p df DOI: http://dx.doi.org/10.1590/S198464872013000200017

26. Santos DK. As produções discursivas sobre a homossexualidade e a construção da homofobia: problematizações necessárias à psicologia. Epos. [Internet]. 2013 [citado em 04 fev 2018]; 4(1):1-24. Disponível em: http://pepsic.bvsalud.org/pdf/epos/v4n1/07. pdf

27. Andreazza TS. Gêmeos monozigóticos discordantes para transexualidade: diferenças neuroanatômicas e psicológica. [Dissertação]. Porto Alegre, RS: Universidade Federal do Rio Grande do Sul/UFRGS; 2012. 62p.

28. Spizzirri G. Transexualismo e neuroimagem. Diagn Tratamento [Internet]. 2012 [citado em 04 fev 2018]; 17(1):32-35. Disponível em: http://files.bvs.br/upload/S/1413- 
9979/2012/v17n1/a2858.pdf

29. Ceccarelli PR. A invenção da homossexualidade. Bagoas. [Internet]. 2012 [citado em 22 mar 2018]; 2(2):71-94. Disponível em:

https://periodicos.ufrn.br/bagoas/article/vie $\mathrm{w} / 2268$

30. Langdon EJ, Wiik FB. Antropologia, saúde e doença: uma introdução ao conceito de cultura aplicado às ciências da saúde. Revista Latinoam Enferm. [Internet]. 2010 [citado em 22 out 2017]; 18(3):459-66. Disponível em: http://www.revistas.usp.br/rlae/article/view/ 4176 DOI: http://dx.doi.org/10.1590/S010411692010000300023

31. Calçado T. Doença: sofrimento e vida nas filosofias de Friedrich Nietzsche e Blaise Pascal. [Dissertação]. Marília, SP: Universidade Estadual Paulista/UNESP; 2009. 127p.

32. Junqueira RD. Homofobia: limites e possibilidades de um conceito em meio a disputas. Bagoas. [Internet]. 2007 [citado em 12 nov 2017]; 1(1): 1-22. Disponível em: https://periodicos.ufrn.br/bagoas/article/vie $\mathrm{w} / 2256$

33. Matias D. Psicologia e orientação sexual: realidades em transformação. Anal Psicol. [Internet]. 2007 [citado em 12 abr 2018]; 1(25):149-52. Disponível em: http://publicacoes.ispa.pt/index.php/ap/articl e/view/436

34. Conselho Federal Psicologia (Brasil). CFP defende e Justiça mantém Resolução 1/99. Decisão do TRF2 manteve as normas da autarquia para atuação dos psicólogos em relação a orientação sexual, que vedam terapias conhecidas como "cura gay" [Internet]. Disponível em: http://site.cfp.org.br/cfp- defende-e-justica-mantem-resolucao-199/

35. Pereira RDB. 0 transexualismo e a alteração do registro civil [Internet]. 2008 [citado em 21 fev. 2018]. Disponível em: http://www.egov.ufsc.br/portal/sites/default/ files/anexos/9899-9898-1-PB.pdf

36. Ministério da Saúde (Br). Portaria no . 457, de 19 de agosto de 2008. [portaria na internet] Diário Oficial da União 19 de ago de 2008. [citado em 09 nov. 2017]. Disponível em: <http://bvsms.saude.gov.br/bvs/saudelegis/sa s/2008/prt0457_19_08_2008.html>

37. Ministério Público (Pará). LGBT: conceitos, direitos e conquistas. [Internet] Belém: CEAF; 2016 [citado em 11 nov. 2017]. Disponível em:

http://www.mppa.mp.br/upload/Cartilha_LGB TI.pdf

38. Dicionário Aurélio de Português Online. [citado em 12 abr 2018]. Disponível em: https://dicionariodoaurelio.com/patologia 39. Morera JAC, Padilha MI. Social representations of sex and gender among trans people. Rev Bras Enferm. [Internet]. 2017 [citado em 12 abr 2018]; 70 (6):1235-43.

Disponível em:

http://www.scielo.br/pdf/reben/v70n6/00347167-reben-70-06-1235.pdf DOI:

http://dx.doi.org/10.1590/0034-7167-20160581

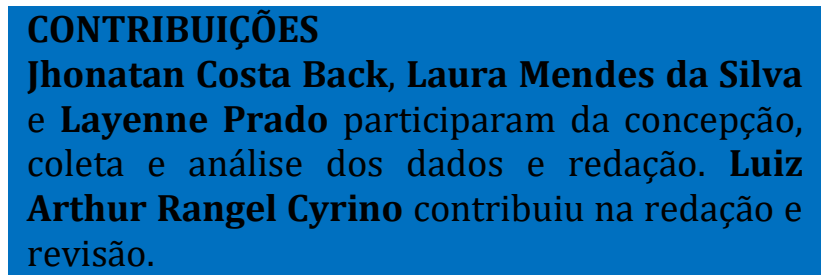

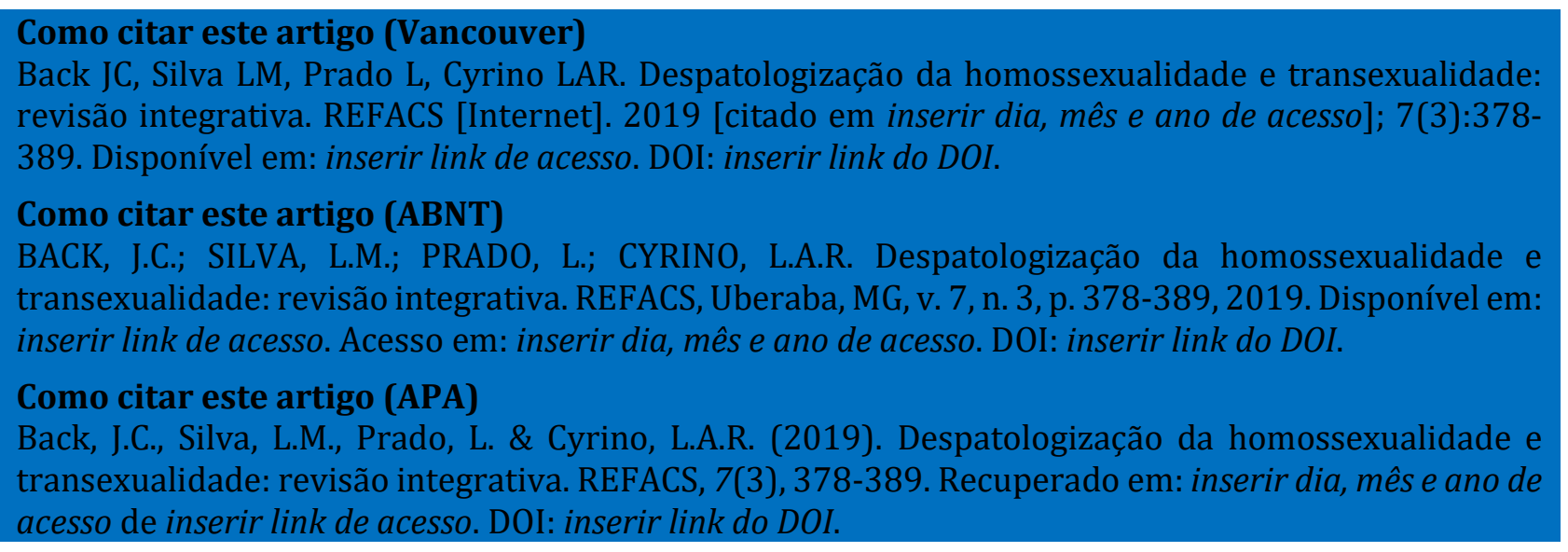

